\title{
EDUCAÇÃo FÍSICA ESCOLAR: CONSTRUINDO CASTELOS DE AREIA
}

\author{
Jose Guilmar MARIZ DE OLIVEIRA*
}

Senhores participantes deste seminário:

Cumpre-me registrar, inicialmente, a honra que sinto em principiar as discussões e reflexões sobre o tema do evento, ou seja, Educação Física Escolar e, ao mesmo tempo, que estou ciente da responsabilidade em tentar preparar, em termos de expectativa e interesse, um ambiente realmente propício para o alcance de seus objetivos.

Tenho claro, neste momento, todo o contexto da Escola ou da escolarização neste pais e nas suas diversas regiôes. Tenho claro os problemas da Escola particular e da Escola páblica, considerando aqui também a função da Escola e os problemas gerais da escolarização. No entanto, acredito que, nesta oportunidade, em função do escopo deste seminário, a consideração desses aspectos é tida como premissa, e que partirei desse ponto em diante, não negligenciando, nem desconsiderando tal contexto, pois o mesmo representa o pano de fundo para minha exposição.

A idéia do título "construindo castelos de areia" mostra uma preocupação, que eu queria trazer em primeiro lugar. Talvez, de início, todos já visualizaram implicitamente no castelo de areia que menciono, a idéia da ocupação de uma praia, e diria, ocupação de uma praia considerados aspectos democráticos de reforma agrária e de proteção ambiental. Visualizo essa praia como conservada e protegida por nós, com vários castelos representando os componentes curriculares de uma Escola. Tenho claro também que essa idéia de castelo não é uma idéia de um feudo, tampouco de um feudo isolado.

Por razōes meramente estruturais, para esta palestra, estou considerando cada castelo tendo certas especificidades. A Educação Física estaria num destes castelos e todos esses castelos da Escola estariam interligados uns com os outros. Vejo então que a nossa Educação Física ou esse "castelo Educaçāo Física" encontra-se nessa praia chamada Escola e que nós temos tentado e estamos procurando constrư-lo arduamente. Um trabalho difícil porque esse castelo não sendo sólido, não estando muito bem edificado, constantemente tem sido destruído pelas águas com o subir da maré.

Não resta dúvida que muitos têm trabalhado com seriedade nessa missão de construção desse castelo, mas tenho notado que falta a essência de uma liga consistente que possa manter o castelo em pe, independente de diferentes formas de acabamento, decoração e retoques indispensáveis e necessários. Assim, tenho visto esforços de diversos colegas, de vários grupos, falando sobre Educação Física Escolar e a cada momento surge mais uma proposta pedagógica, mais um projeto pedagógico, mais uma idéia de grupos representando Secretarias de Estado, ou Secretarias Municipais. Propostas diferentes em muitos sentidos, o que até seria saudável, mas, no entanto, entendo que as diferenças existem até mesmo essência ou naquilo que deveria ser específico da Educação Física.

Vejo também, na procura dessa construção de um castelo mais sólido, que neste próprio seminário existe uma tentativa de sair um pouco das tendências que nós temos visto nesta última década ou altimos 20 anos, nos quais congressos de Educação Fisica ou eventos que tratam do assunto Educação Física têm apresentado muitos assuntos misturados, incluindo a discussão de vários fenômenos e manifestaçōes culturais distintos, como o jogo, o esporte, e a dança. Tal tentativa visa buscar respostas para concretizar a base dessa construção.

\footnotetext{
- Escola de Educacaáo Fisica da Universidade de Sāo Paulo.
} 
Uma outra preocupação é que a construção ou a tentativa de construção desse castelo tem envolvido prioritariamente aqueles que mais diretamente estão ligados aos aspectos especfficos da área: nós, professores de Educação Física. Assim sendo, talvez por pensarmos a área muito estreitamente, por várias razões (algumas das quais historicamente muito bem entendidas), não demos conta ainda da necessidade dessa liga, a essência da Educação Física.

Para mostrar um exemplo disso, ou vários exemplos, temos realizado algumas pesquisas onde, junto à pessoas de várias gerações mais próximas perguntamos: (a) o que elas entendem por Educação Fisica, e (b) o que elas acham da Educação Física. E com certa tristeza que ouvimos declaraçóes do tipo "eu não aprendi nada em Educação Física", ou que "passei 11 anos pela escola do 1o. e 20. graus e muito pouco da Educação Física eu aproveito em minha vida" ditas freqüentemente. Ontem, tivemos aqui na Escola de Educação Física da Universidade de São Paulo, um exame de qualificação de mestrado em que uma das participantes da banca, professora da Faculdade de Educação, colocou muito claro a idéia que ela tem da sua Educação Física na escola. Em suas palavras: "a professora dava a bola para o jogo das alunas, pura e simplesmente". Esse é mais um exemplo mostrando que nossos esforços até agora não têm sido tão eficazes e sólidos assim.

Uma outra evidência dessa nossa falta de estrutura tem sido demonstrada em nosso curso de licenciatura da Escola de Educação Física da Universidade de São Paulo, através de um trabalho que realizo há 5 anos, no qual é solicitado aos alunos da disciplina "Introdução à Educação Física" que relatem como foi a sua experiência com a Educação Física na escola. São jovens de 18/19 anos que têm uma experiência muito clara e recente do que foi essa Educação Física e é com grande pesar que a maioria responde que foi uma experiência não agradável. E se foi uma experiência não agradável, por que eles procuram a preparação profissional nessa área? Podemos verificar uma variedade de respostas tais como: "porque é o curso mais fácil na atualidade dentro da formação universitária"; e até aqueles que falam que "eu quero aprender a ensinar algo que não me foi ensinado e a fazer aquilo que não foi feito comigo", numa visão bastante romântica e até idealista.

Uma outra preocupação constante dessa mostra de um não entendimento ou da não solidez da nossa área é a situação que temos ainda hoje - novembro de 1990 - representada por depoimentos de alunos da Escola de Educação Física da Universidade de São Paulo, que em contato com outros alunos da Universidade - que de certa forma tiveram aulas de Educação Física durante sua fase de escolarização - observam uma desinformação destes sobre o curso de graduação em Educação Física. Perguntas assim: "O que vocês estudam na Educação Física?", "Vocês têm caderno?", "Vocês têm livros textos?", revelam uma visão bem nebulosa da nossa área, após nossa atuação durante 11 anos na escola de 1o. e 20. graus.

Indo um pouco além, numa pesquisa realizada em 1982, com 31 escolas de 1o. e 20. graus da DRECAP 3, aqui na região de São Paulo, tivemos também que ouvir, olho no olho, frente a frente, a resposta de 28 diretores que foram unânimes em registrar que o maior problema de suas escolas era representado pelas aulas de Educação Física e se pudessem, amanhã mesmo, eles a retirariam do currículo. Assim colocado, acredito que não é essa a Educação Física que queremos. Eu diria que, de certa forma, essa "culpa" não cabe tão somente a nós da área de Educação Física. Precisamos por várias outras razões e pelo próprio desconhecimento desses, no caso que citei, dirigentes de escolas, fazer sentir, sensibilizar, e até mesmo despertar e mostrar para os outros habitantes da nossa praia, incluindo aqueles responsáveis pela coordenação dos esforços individuais em prol do coletivo, as nossas verdades, se é que existem, claramente elaboradas e explícitas, e que a sustentação e edificação do nosso castelo é legítima ou mostrar aquilo ou em que nível estamos discutindo e percebendo o estado da Educação Física Escolar atual. E essa foi a idéia também de organizar este seminário, na tentativa de promover uma discussão de determinados temas que, a algum tempo atrás, de nada ou de muito pouco adiantaria.

Diferente de outros momentos em que professores de Educação Física tão somente discutem o dia-a-dia na escola, a nossa estratégia tem sido caracterizada por tentar sensibilizar autoridades, diretores de escolas, delegados de ensino, supervisores de ensino e outras pessoas relacionadas com a organização da escolarização e não somente professores de Educação Física. Então, após tal consideração, eu tecerei alguns comentários sobre questões básicas; nosso castelo nunca será edificado solidamente se essas questōes não forem respondidas. 
Uma questão básica é que esta área, até agora chamada de Educação Física, tem sido questionada ou pede-se uma definição dessa área de conhecimento, inclusive um conhecimento acadêmico e que deixe claro também que ela hoje, para nós, não trata somente de assuntos relacionados com o ensino ou com a escolarização. Por que tocar nesta questão básica? Porque na própria Escola de Educação Física da Universidade de São Paulo, pessoas alheias à área de Educação Física pensam que, ou referem-se à Educação Física, tão somente como aquilo que ocorre na escola. Entendo que isso faz parte da evolução da área. Vários países passaram por essa mesma situação; no entanto, hoje, quero deixar claro que o advento do bacharelado e a relação entre bacharelado e licenciatura propicia processos distintos de preparação profissional. No nosso caso, minha preocupação e idéia principal aqui na Escola de Educação Física da Universidade de São Paulo, é valorizar profissionalmente o professor, quero dizer, dar um valor muito grande à licenciatura.

Uma outra preocupação que advém desta mesma questão básica é esta idéia, esta verdade, ou mito, ou preconceito que se tem, ou o preconceito que nós mesmos produzimos em função de várias incompetências, ou de várias deficiências, ou porque a sociedade desta praia perpetua os mesmos. $E$ o preconceito que somos uma classe secundária na escola. Nós já vimos isso em vários depoimentos de colegas professores, por escrito inclusive, relatando que estamos em uma área marginal da escola, e que não participamos da escola, por várias razões. Eu diria, até por deficiência da própria preparação profissional. E esta mesma colocação eu ouvi de 28 diretores de escolas da DRECAP-3/São Paulo.

Outra questão básica que a meu ver merece maior consideração e passa às vezes despercebida, e digo que $e$ um detalhe pequeno, mas importante, refere-se à propria expressão, à própria denominação, ao proprio termo Educação Física que é inadequado e pouco questionado, não tendo recebido a devida consideração. Eu aproveitaria para trazer aqui o exemplo da Educação Artística. Na escola, nós temos a Educação Física e também a Educação Artística. Não se tem este componente curricular Educação Artística chamado de arte ou artes; foi rotulado de Educação Artística. Por outro lado, quando se fala, por exemplo, em matemática, química, e história, não se fala em educação matemática, educação química, ou em educação histórica. $E$ até diria que é bom que isso aconteça porque já se elimina um problema sério: Se fôssemos relacionar a área de Educação Física com a área de Física, e utilizássemos o mesmo pensamento seria difícil entender a quê Educação Física estaríamos nos referindo, ou ao ensino da Física ou ao ensino de alguma outra coisa relacionada com "física". Considero esta inadequação como uma preocupação importante na definição da área, mas não vejo como uma preocupação clara e definida da parte de autoridades escolares; e poucas pessoas da área até agora questionaram, ou preocuparam-se com isso.

Uma outra questão básica a ser seriamente entendida e discutida, $€$ a questão da Educação Física como componente curricular, naquela idéia de discussão sobre "atividade", sobre "área de estudo", e sobre "disciplina". Muito freqüentemente, pelo não entendimento desta questão, saímos a campo, saímos a público, defendendo a Educação Física enquanto "disciplina", sem saber o que isso significa. De um ponto de vista lógico e claro, tratando-se da Educação Física enquanto "atividade", acredito que a situação atual é clara e acredito também que talvez nem precisássemos do licenciado em Educação Física por ser considerada simplesmente atividade por atividade. Se pretendermos que a Educação Física seja entendida como "disciplina" na escola, vamos ter que provar muita coisa. Então essa questão de "disciplina" curricular torna-se essencial; questão que eu, assim como muitos, queremos retomar, para ver a Educação Física tendo um lugar de respeito, de mérito, comparado a outras "disciplinas" da escola. Fala-se que para ser disciplina curricular na escola nós devemos ter claramente definido o conteúdo proprio a ser ensinado numa instituição escolar, e que esse conteúdo deveria ser fruto de um conhecimento sistematizado e acumulado historicamente. Agora comecem a se perguntar: Que conteudo é esse? Fala-se também que a legalidade ou o aspecto legítimo do trabalho competente no interior da escola não virá através de decretos. Isso é bem entendido; mas virá pelo processo de produção do conhecimento. Porém, produção do conhecimento em quê? Fala-se, nesta mesma linha de pensamento, que a Educação Física deve ser disciplina acadêmica, que ela deve ter um objeto de estudo claro e proprio. Basta uma leitura rápida pelos trabalhos mais evidentes na nossa área e vemos que o objeto de estudo da Educação Física é, entre outros, a expressão corporal, é a expressão corporal como linguagem,

Rev. paul. Educ. Fts., São Paulo, 5(1/2):5-11, jan./dez.1991. 
é o movimento humano, é representado pelas formas de cultura corporal, é a educação do movimento,etc. E aí nós vemos uma tradução muito irresponsável e sem muita reflexão, de um termo do inglês que é "Movement Education", para "Educação do Movimento". Na minha percepção, movimento não é educável, quer dizer, quem é passível do processo de educação é o ser humano e não o movimento. Assim sendo, aquela tradução do inglês foi mal feita e utilizada de forma grosseira em vários momentos. Então, o objeto de estudo da Educação Física é a educação do movimento? A meu ver, repito, o movimento não é educável. Educação pelo movimento? Aí várias confusões se instalam: Alguém guer alfabetizar alguém pelo movimento? Alguém quer ensinar matemática a alguém pelo movimento. É de certa forma uma outra confusão, pois nós não temos claro o que é especifico do nosso objeto de estudo. $\mathrm{E}$ ainda mais, são os jogos? $€$ a dança? São as lutas? $€$ a ginástica? $€$ o esporte? € o malabarismo? E a mímica? São as representações simbólicas? Quero dizer, não consigo encontrar neste amontoado de "objetos de estudo", algo que seja único e específico da Educação Física. Vejo, após estes exemplos, como estratégia ou como forma de melhor direcionar o assunto, que talvez por nosso objeto de estudo as discussões devessem caminhar mais para a idéia de educação para o movimento, tanto quanto se fala de uma educação para o lazer. Assim acredito ser algo bastante legitimo. quando se procuraria o entendimento e a compreensão da importância do movimento para o ser humano no seu cotidiano como um todo, não só na prática social, individual ou coletiva. Notem que essa idéia de educação para o movimento, ou educação sobre o movimento é algo muito intrínseco, algo não apenas prático ou que ocorre somente quando "agora eu vou praticar Educação Física".

Essas colocações tornam-se de certa forma absurdas quando trago alguns exemplos, quando essa prática social torna-se o fazer pelo fazer, entendida como o exemplo que apresento do carteiro que anda o dia todo entregando cartas; do lixeiro que corre o dia todo atrás do caminhão, jogando lixo dentro do mesmo; e do carregador do caminhão de carne que carrega aqueles pedaços de carne durante algumas horas por dia. Acredito que não seria lúcido, não seria justo que eles me falassem: "eu trabalhei, andei, entreguei cartas, corri, carreguei peso, e agora vou "andar", "agora vou correr", ou "agora vou fazer musculação". Essa não é a idéia de Educação Física que tenho hoje. Educação Física faz parte do cotidiano, da minha existência, do momento em que vivo. Tem-se claro, que essa educação para o movimento ou sobre o movimento teria um objetivo especifico da orientação do individuo, do ser humano, tanto para o entendimento do seu mundo de trabalho, e uma educação relacionada com o lazer, em oposição ao trabalho. Através desta educação o indivíduo poderá utilizar seus momentos de lazer, se é que os tenha, ou se a situação o permitir. Vai talvez utilizar seus momentos de lazer sabendo da importância que tem o movimento, a atividade motora.

Esta é uma questão que traz pela sua própria indefinição vários outros problemas, dentre os quais eu destaco um relacionado com a avaliação do conhecimento adquirido pelo aluno durante as aulas de Educação Física. Ora, se esse é um componente curricular nós teremos que ter bem claro aquilo que a criança da primeira série que passou pela Educação Física deve ter aprendido ou adquirido ao final de um ano, ou um semestre, em termos de conhecimento. Avaliar conhecimento? Que tipo de conhecimento? Será que 6 conhecimento de quantos jogadores fazem parte de uma equipe de futebol? Quero dizer, creio que ninguém precisa ir a escola para aprender isso. Então, é mais uma questão aqui colocada.

Uma outra orientação, uma outra ajuda para um melhor entendimento desta questão, relacionada com área de conhecimento, acadêmico ou não - eu diria, acadêmico sim, porque temos usado a justificativa que a mesma existe no âmbito universitário - é que na Educação Física não se estuda sర o Esporte, o Jogo, a Ginástica e a Dança. Estuda-se o significado e o entendimento do movimento em toda e qualquer atividade motora humana. Não somente uma prática social baseada em reflexão filosర6fica, teórica e intencional. Não só relacionados a temas sócio-políticos mas também biológicos. E é a escola que pode propiciar esses entendimentos. Em função disso retomamos às questões básicas já apresentadas: ensinar o quê através da Educação Física na escola? Se é que é uma disciplina curricular, ignorando o conceito de "atividade" curricular, ensinar o quê? $\mathbf{E}$ aí tem aparecido a preocupação de algumas pesquisas hoje tentando verificar claramente o que é conteúdo de aulas de Educação Física. Como exemplo, será que o jogo de futebol se aprende na escola? Enfatizo novamente a questão feita 
anteriormente. Ensinar o quê em uma aula de Educação Física? Ensinar a dançar? Ensinar a dança? Será que a lambada se aprende na escola? As implicações sociais, políticas, psicologicas, biológicas, econômicas, ecológicas do jogo de futebol, pode-se e deve-se aprender na escola. As implicaçōes sociais, políticas, psicológicas, biológicas, econômicas e ecológicas de dançar lambada, pode-se aprender na escola. Vejam a diferença de uma coisa com outra. Dentro desta mesma idéia, de questão básica sobre o que se deve ensinar na aula de Educação Física, aparece um momento da confusão que imagino relacionado com a idéia do lúdico, a idéia do jogo. Quer dizer, volto àquela situação anterior: compete à Educação Fisica ensinar o jogo? O jogo $e$ um fenômeno ou é um momento antropologico muito mais antigo do que a propria Educação Física? Acredito que o jogo não $\epsilon$ objeto especifico da Educação Física. Vejo sim o ládico como uma estratégia riquíssima para que qualquer professor, de qualquer componente curricular, coloque em prática em suas aulas. Através do lúdico vou ensinar geografia, matemática, física, português, etc. Repito, não considero o lúdico como algo inerente, próprio, específico da Educação Física.

Se formos entender que na aula de Educação Física alguém vai aprender movimento eu diria que vamos cair naquela crítica de que aprender movimento relaciona-se também com o adestramento de pessoas. Da mesma forma que o ser humano aprende movimento, o urso aprende, o elefante aprende, a foca aprende. Se $\varepsilon$ para aprender movimento será que o tempo aproveitável de duração de uma aula de Educação Física $€$ suficiente? Já temos pesquisas nessa área, talvez pesquisas que ainda não chegaram àqueles que estão trabalhando na escola. Tive algumas evidências disso quando trabalhava na Faculdade de Educação Física de Sorocaba; era um privilegio muito grande porque da janela das salas de aula nós tínhamos uma visão clara da quadra/pátio de uma escola. E viamos em questão de conteúdo o que se ministrava na aula de Educação Física numa escola particular de primeira linha de Sorocaba. A professora dando o mesmo conterudo, durante o semestre, e por exemplo, aquela situação de "ensinar" o movimento, "ensinar" a bandeja do basquetebol para os alunos. Notou-se então aquela situação que acredito que todos nós já conhecemos: São duas fileiras em frente a tabela/cesta de basquetebol, uma fileira em cada tabela, uma bola para o primeiro aluno da fileira e a tarefa: quicar a bola, driblar a bola, tentar fazer a cesta em três tentativas no máximo, e ir para a outra fileira/tabela, continuando o ciclo da tarefa. Tínhamos uma situação de "laboratório", registrando várias situações, inclusive cronometrando a participação na "tarefa": a criança pega , aproximadamente a cada 4 minutos, nessa bola para executar uma tarefa motora, em uma aula de 45 minutos. Então eu pergunto: o que $e$ que ela vai reter de aprendizagem de movimento em uma situação dessas? É até contra as próprias teorias de aprendizagem motora. E nesse momento, além disso, temos evidentes alguns outros problemas de uma aula dessas. A criança tem que ser entendida no seu contexto geral, e nas suas caracteristicas e expectativas. Ela não espera pacientemente 4 minutos para arremessar a bola à cesta. Ela puxa o calção do colega da frente, ela bate na cabeça do outro, ela desamarra o tênis do outro. Uma situação clara, que o professor, pela sua própria montagem da tarefa, perde o controle da aula. Diria tambem, dentro de uma concepção de escola brasileira, a criança passa muito pouco tempo na escola. Agora, queremos que ela aprenda o movimento na escola; isso especialmente na aula de Educação Física. Proponho para uma solução, a discussão séria desses problemas. A criança deve ou vai aprender na escola as implicaçôes do correr. Vai aprender as implicações do saltar, em todas as suas dimensões. Vai aprender sobre a ginástica e suas implicaçôes, o que é diferente, o oposto de ir correr na escola, ir saltar na escola ou ir fazer ginástica na escola. E ar trazemos na concepção anterior, a idéia de que a criança, na "disciplina" curricular Educação Física, traga até tarefas de casa. Ela aprendeu como fazer, o sentido e implicą̧ões do movimento; agora ela faz a tarefa em casa e traz para discussão em classe e em função dos objetivos da escola. Da mesma forma a idéia do saltar, correr, fazer ginástica, quando se fala em, e até se admite que a Educação Física na escola existe para manter a forma do aluno. Eu diria que nas aulas de Educação Física vou ensinar a como manter a forma e não manter a forma nas aulas de Educação Física. Seria ingênuo não entender claramente que, fora da escola, a criança corre, a criança salta, a criança chuta bola, a criança arremessa pedra, a criança dança, a criança roda pião, a criança pula amarelinha, ela pula sela, etc. Muito mais do que o faria na própria escola. Ela movimenta-se muito mais fora da escola e as vezes nós, no nosso idealismo, ou na nossa ignorância mesmo, colocamos a criança frente à execução de uma tarefa motora, 
por exemplo, andar sobre uma trave, que tem 5 ou 10 centímetros. Perante a essa situação ela não consegue andar sobre a trave; lá, fora da escola ela trepa no muro, ela corre em cima do muro, ela sobe em árvore. Quero dizer, é uma situação artificial, e assim desconsideramos muitas vezes o que ocorre fora da escola.

Outra questão básica que eu traria é a idéia do tratamento especial que deve ser dado a uma seriação, a uma seqüência de conteúdos em diferentes séries, desde a pré-escola até o 20 . grau. E á́ temos claro um problema atual. Estamos com uma dissertação de mestrado analisando esta questão de prática de ensino e planejamento, na qual professores da rede estadual têm evidenciado: alguém trabalha com o volibol durante vários semestres, isto $e$, com o mesmo conteúdo. $\mathbf{E}$ o professor admite isso. Admite que é assim mesmo e que vai continuar a fazer isso porque é o que ele sabe fazer. Então é o conteúdo do volibol em várias séries, a mesma aula, durante vários anos. Esta é a questão então, relacionada ainda com o conteúdo: se Educação Física é sempre o ensinar o volibol, o esporte, ou ensinar a dança? Quando vai haver uma diferenciação, em termos de conteúdo, entre o que é ensinar da 1a. série do primeiro grau até a 3a. série do segundo grau?

Vejo uma outra questão básica e talvez. mais diretamente ligada às autoridades escolares. Numa problemática que traz duas variáveis, ou que traz dois fenômenos que considero distintos: a Educação Física e o Esporte. Vemos que é uma situação clássica onde tenta-se utilizar o jogo com características da modalidade esportiva, voleibol, basquetebol, handebol, entre outros, nas aulas de Educação Física e aí causam problemas como os anteriormente citados, de conteúdo das aulas. Este é um aspecto desta questão básica. Um outro é a idéia de formação de equipes esportivas representativas das escolas para participar de campeonatos. A autoridade escolar geralmente interpreta mal a função do professor de Educação Física e vê como sinônimo as duas coisas, as duas tarefas profissionais. Talvez a própria história da Educação Física Escolar nesse país nos mostre isso. Por outro lado, este entendimento, às vezes, é reforçado quando vejo que existe no momento atual, e passado tambem, uma duplicidade de instituições. Vemos os mesmos alunos-jogadores, atuando também na instituição clube. Quando participci da orientação técnica da equipe de São Paulo no Jogos Estudantis Brasileiros (JEB's) em Porto Alegre na década de sessenta, fiz um levantamento com nossos alunos-jogadores, agora, então, representando a instituição escola; constatei que eles vieram da instituição cluhe, caracterizando assim essa duplicidade de esforços. Ao mesmo tempo a má informação nos traz a cópia do modelo americano. E muitos querem trazer a cópia do modelo americano, porque é na escola que se formam os atletas nos Estados Unidos, com muitos problemas que não conhecemos. A outra estrutura, a clubística, não existe nos Estados Unidos. Então não resta outra alternativa. A concepção de escola americana é outra: a criança passa, aproximadamente, das oito até às quinze horas na escola e não como a nossa escola brasileira que tem 3 ou 4 turnos em um dia só, para 3 ou 4 populações de alunos. $E$ até ingenuidade querer comparar o modelo americano com o modelo brasileiro. As escolas americanas têm suas necessidades básicas contempladas, tais como giz, quadro negro, salas de aula com carteira, sem goteira, livros, biblioteca, como alguns exemplos. Tenho claro também, que em certos locais e em certas circunstâncias deste Brasil, a escola é sim o local e o único local, onde talvez. o aluno tivesse a chance de conhecer uma quadra de basquetebol, uma bola de volibol, uma bola de handebol, porque talvez aquele clube esportivo e social daquele local, admita somente uma elite e ele não possa assim participar. No entanto, apresento um outro componente que talvez argumente contra isso. Na minha concepsaao de esporte, indiferente de nível sócio-econômico e de raça - e temos aqui em São Paulo essa evidência - se o elemento tiver potencial para o esporte, se for uma estrela do esporte, se ele for excelente saltador do salto triplo, ou se for um excelente volibolista ou jogador de basquetebol, "até sendo negro" ele participa, por exemplo, do clube Pinheiros. Não vai ser esta a barreira para que ele entre em um clube socialesportivo de elite.

Talvez. a última questão básica é que no âmbito da Educação Física Escolar entendemos e estamos tentando justificar e trazer para responsabilidade deste componente curricular, todas as funções da escola. Agora a pergunta é: o que dela é específico, o que está sendo ensinado quando propomos que para a Educação Física ou na Educação Física vai ser desenvolvida a socialização, o senso crítico, a cidadania, e tudo mais? Eu diria ótimo; se a Educação Física faz. isso, as outras matérias tem que fazer o 
mesmo. Nas aulas de matemática também deve-se zelar pela socialização, pelo senso crítico e pela cidadania, e não so nas aulas de Educação Física. Só que na ausência de uma essência de conhecimento específico, buscamos essa justificativa. E queremos para nós essas responsabilidades; que a Educação Física se preocupe com tudo isso. Tivemos recentemente um trabalho de mestrado aqui na Escola de Educação Fisica da Universidade de São Paulo, no qual o autor analisou três grupos distintos na escola: quem faz Educação Física, quem não faz Educação Física e quem só pratica esporte na escola. 0 trabalho, com suas limitações de dissertação de mestrado, mostrou que o aluno que não faz Educação Fisica tem o mesmo nível ou grau de socialização de quem faz Educação Física. Então poder-se-ía considerar que o não fazer Educaçāo Física $\epsilon$ algo que não vai ser prejudicial, em termos de socialização, porque, na escola, não é só na aula de Educação Física que se trata da socialização.

Eu diria que esses nossos esforços, nesse seminário que hoje tem início, diante dessas questões básicas, estarão diretamente voltados para a tentativa de, num período de tempo, que espero bastante breve, encontrar os elementos indispensáveis para a consolidação do nosso castelo. Caso contrário, poderemos ser varridos de vez da praia, sem sequer ter tido a chance de contribuir, dentro da significância individual e limitada no contexto geral da escola, para fortalecer o inter-relacionamento dos castelos e tentar evitar que num futuro breve a praia seja invadida para fins não tão necessários e nobres, seja poluída de modo irreversível ou até que nem mesmo a praia exista mais. Por outro lado, gostaria de ressaltar que, se naturalmente e racionalmente a Educação Fisica não for considerada através de um processo imparcial, democrático e exaustivo, justo e honesto, como legitima e com funções coerentes com a instituiçāo escola, cabe-me lembrar que nem por isso o estudo, a compreensão, a explicação de temas relacionados com as condutas e intenções motoras do ser humano, deixarão de merecer consideração. Essas decisões não nos cabem de forma irrestrita, mas nossas respostas a estas questões básicas aqui colocadas, serão fundamentais para definições futuras. E e com essa preocupação e expectativa que espero que este seminário represente uma oportunidade a mais para discussões sérias e propícias relacionadas com a nossa Educação Física Escolar.

Obrigado. 